\title{
EVALUATION OF THERMOSYPHON APPLICATION FOR COOLING THE MODULAR AUTOMATED CONTROL SYSTEMS
}

\author{
Konstantin Yu. Ushakov ${ }^{1}$, Andrey N. Peters ${ }^{1}$, Alexander R. Bogomolov ${ }^{2}$, and Elena Yu. \\ Temnikova ${ }^{1, *}$ \\ ${ }^{1}$ Kuzbass State Technical University named after T.F. Gorbachev, 650000 Kemerovo, \\ Russia \\ ${ }^{2}$ Kutateladze Institute of Thermophysics SB RAS, 630090 Novosibirsk, Russia
}

\begin{abstract}
The experimental setup for studying operation effectiveness of the closed two-phase thermosyphon $\mathrm{s}$ aimed at the development of heat exchangers without disturbing the process of air circulation inside the module of control system, which can maintain the required temperature that provides effective heat removal from the zone of module equipment are elaborated. The primary results of experimental researches are presented.
\end{abstract}

\section{Introduction}

The autonomous modules of control systems have high heat release. To avoid equipment overheating and ensure its trouble-free operation, it is necessary to remove released heat. At that, the certain quality requirements should be obeyed, namely the purity of the working medium used in the cooling system. For example, to cool the modular automated control systems of electric calorific installations for air supply to the mines, the refrigerating units that match the requirements are used. However, the cost of one unit in average is about $2 \mathrm{mln}$. rubles; moreover they are quite cumbersome.

To date, there are the cooling systems used in various heat-exchanging devices based on the evaporation-condensation cycle: the closed two-phase thermosyphon $\mathrm{s}$ of different designs [1-2]. They are considered to be effective in comparison with other elements of cooling systems because they have high heat transfer characteristics and easy to be manufactured [1, 3-4]. Until now, thermosyphon introduction is not large-scaled, because, despite the relatively simple mechanism of thermosyphon s operation, the general theory of heat transfer processes in thermosyphon $\mathrm{s}$, which takes into account a large set of physical processes in the zones of evaporation and condensation, in the vapor channel, and moving film of condensate, has not been developed [15].

The objective of this work is the creation of experimental setup for studying operation effectiveness of the closed two-phase thermosyphon s aimed at the development of heat exchangers without disturbing the process of air circulation inside the module of control

\footnotetext{
${ }^{*}$ Corresponding author: teu.pmahp@,rambler.ru
} 
system, which can maintain the required temperature (about $60^{\circ} \mathrm{C}$ ) that provides effective heat removal from the zone of module equipment.

\section{Experimental setup}

The scheme of experimental setup for studying the process of heat removal by means of two-phase closed thermosyphon $\mathrm{s}$ is shown in fig. 1.

It is box 1 with confusers 2 attached from different sides to feed cold air to the upper part and hot air to the lower part (see fig. 1, arrows). To prevent hot and cold air mixing, there is sealed partition 3. In box 1 , there are thermosyphons, consisting of a series of vertical copper tubes with the $8-\mathrm{mm}$ diameter, $400-\mathrm{mm}$ height, connected by a single horizontal tube: manifold. The working substance is freon R141b. It is a colorless transparent liquid, whose physical and chemical properties are close to the properties of $\mathrm{R} 11$ and $\mathrm{R} 113$. The chemical formula is $\mathrm{CH}_{3} \mathrm{CFCl}_{2}$. The boiling point is $32.1^{\circ} \mathrm{C}$. The degree of tube filling is $20 \%$, excluding the manifold.

The closed two-phase thermosyphon is a vertical wick-free heat pipe, where coolant transfer from the zone of evaporation to the zone of condensation occurs due to the lifting force. The working substance (freon) allows transfer of a large amount of energy due to evaporation in the bottom part of the unit through the heat supply from hot air. Vapor produced in the evaporation zone rises in the central part to the condensation region due to the buoyancy effects, and latent heat of phase transition is released there due to cold air. Condensed vapor goes back to the evaporation zone over the inner side surface of thermosyphon under the action of gravity [3].

The temperatures of hot and cold air and their flow rates were measured during the experiment at setup inlet and outlet.

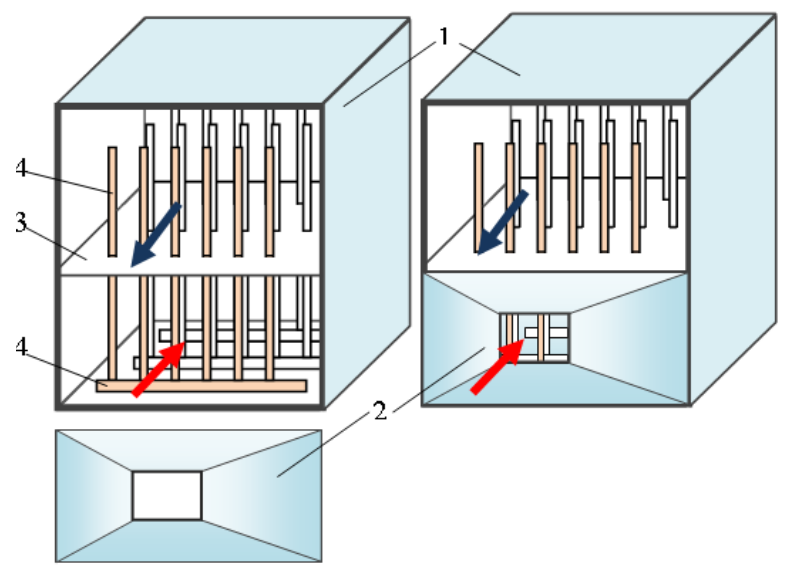

Fig. 1. Scheme of experimental setup: 1 - box; 2 - confusor; 3 - partition; 4 thermosyphon.

\section{Results}

The diagram of changes in the hot and cold air temperatures along the setup length was plotted on the basis of temperature measurements; it is shown in fig. 2 . It can be said that hot air cooling by $21.6^{\circ} \mathrm{C}$ leads to cold air heating at the top by $4.2^{\circ} \mathrm{C}$.

The average temperature difference of $70^{\circ} \mathrm{C}$ was determined. The heat balance was calculated, and it was found out that heat removed from hot air through the thermosyphon 
(evaporation area) was $0.889 \mathrm{~kW}$, and heat supplied to cold air (condensation zone) was $0.747 \mathrm{~kW}$, and the difference (losses) was $19 \%$. The heat transfer surfaces were calculated from the geometrical dimensions of thermosyphons in the zones of condensation and evaporation; they were $0.104 \mathrm{~m}^{2}$ for the evaporation zone and $0.219 \mathrm{~m}^{2}$ for the condensation zone. Then, the heat flux densities for these zones were $8.58 \mathrm{~kW} / \mathrm{m}^{2}$ and 3.41 $\mathrm{kW} / \mathrm{m}^{2}$, respectively.

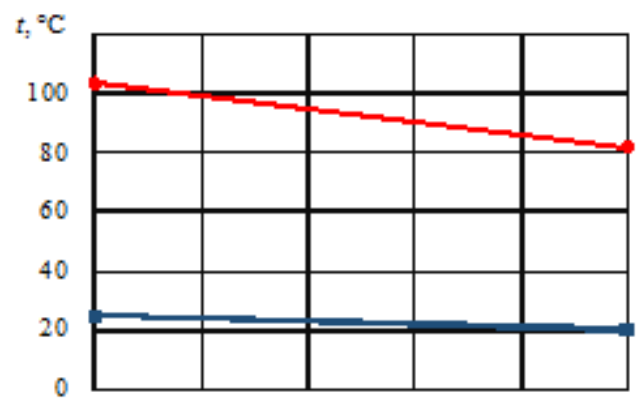

Fig. 2. Temperature change along the length.

\section{Conclusion}

It can be concluded that thermosyphon operation should be studied more accurately and comprehensively, the optimal degree of working medium filling in the tubes should be determined, and the lengths of the zones of freon boiling and condensation should be found.

Further, it is expected to carry out temperature measurements on the thermosyphon walls in the lower and upper parts aimed at determination of air heat transfer coefficient, temperatures of freon boiling and condensation by different methods using the data of numerical and experimental studies of other authors [1-6]. Thermal resistance, which is the main criterion for effective work of thermosyphons, will be determined, and the main contribution is made by the evaporation zone [6]. It is known that the heat transfer characteristics of thermosyphons are affected by many factors: the amount of charged coolant, its thermal-physical properties, lengths of the zones of heating (evaporation) and condensation and cooling conditions in the condensation zone. The large number of influencing factors poses the problem of finding the optimal design for the cooling system on the basis of the two-phase closed thermosyphons, which is important for the specific conditions of their application [4].

The developed model of experimental setup will be the prototype of a heat exchanger, which can be used to cool various equipments. In particular, to cool the modular automated control systems for electric calorific installations for supplying air to the mines, where the refrigeration units with the cost of $2 \mathrm{mln}$. rubles each are used today.

\section{References}

1. M.K. Bexrodnyi, I.L. Pioro, T.O. Kostyuk, Transfer processes in two-phase thermosyphon systems. Theory and practices, (Fakt, Kiev, 2005)

2. Al-Ani Maaz Abdulwahed Zib, The features of hydrodynamics and heat and mass transfer in thermosyphons for application in thermal-power equipment (Tomsk, 2011)

3. G.V. Kuznetsov, M.A. Al-Ani, M.A. Sheremet, Bul. TPU 318, 4 (2011)

4. V.Yu. Kravets, V.I. Konshin, N.S. Vaneeva, , East. Eur. J. Ent. Tech. 2, 5 (2014)

5. A.S. Krasnoshlykov, G.V. Kuznetsov, Int. En. Syst. 1 (2015)

6. V.Yu. Kravets, V.I. Konshin, E.N. Pismennyi, Mod. Inf. El. Tech. (2014) 